\title{
HCH and DDT in Sediments from Marine and Adjacent Riverine Areas of North Bohai Sea, China
}

\author{
Wenyou Hu - Tieyu Wang $\cdot$ Jong Seong Khim • \\ Wei Luo $\cdot$ Wentao Jiao $\cdot$ Yonglong Lu $\cdot$ Jonathan E. Naile • \\ Chunli Chen $\cdot$ Xiang Zhang $\cdot$ John P. Giesy
}

Received: 14 September 2009/ Accepted: 13 December 2009/Published online: 1 January 2010

(C) Springer Science+Business Media, LLC 2009

\begin{abstract}
Residues of organochlorine pesticides (OCPs), hexachlorocyclohexanes (HCHs), and dichlorodiphenyltrichloroethanes (DDTs) and their environmental risks in surface sediments collected from marine and adjacent riverine/estuarine areas in the northern Bohai Sea, China, were investigated. Concentrations of $\Sigma \mathrm{HCH}$ and $\Sigma \mathrm{DDT}$ in sediments ranged from below detection $(<\mathrm{LOD})$ to $1964.97 \mathrm{ng} \mathrm{g}^{-1}$ dry wt (dw; mean, $92.51 \mathrm{ng} \mathrm{g}^{-1} \mathrm{dw}$ ) and $<$ LOD to $86.46 \mathrm{ng} \mathrm{g}^{-1} \mathrm{dw}$ (mean, $9.23 \mathrm{ng} \mathrm{g}^{-1} \mathrm{dw}$ ), respectively. Concentrations of $\mathrm{HCH}$ and DDT were generally higher in marine than riverine sediments. Concentrations of $\mathrm{HCH}$ and DDT residues found in the present study were higher than those reported in marine and river/ estuary sediments from other areas of the world. The source of $\mathrm{HCH}$ in sediments could be explained by the
\end{abstract}

W. Hu · T. Wang · W. Luo - W. Jiao · Y. Lu ( $₫) \cdot$ C. Chen · X. Zhang

State Key Laboratory of Urban and Regional Ecology, Research Center for Eco-Environmental Sciences, Chinese Academy of Sciences, Beijing 100085, China e-mail: yllu@rcees.ac.cn

W. Hu $\cdot$ W. Jiao $\cdot$ Y. Lu $\cdot$ C. Chen $\cdot$ X. Zhang Graduate University of Chinese Academy of Sciences, Beijing 100039, China

\section{J. S. Khim}

Division of Environmental Science and Ecological Engineering, Korea University, Seoul 136-713, South Korea

J. E. Naile · J. P. Giesy

Department of Veterinary Biomedical Sciences and Toxicology Centre, University of Saskatchewan, Saskatoon SK S7J 5B3, Canada

\section{J. P. Giesy}

Department of Zoology, Center for Integrative Toxicology, Michigan State University, East Lansing, MI 48824, USA large amount of historical use, while DDT seemed to be a combination of erosion of the weathered soils and longrange atmospheric transport. Concentrations of $\mathrm{HCH}$ in sediments from the study areas did not exceed sediment quality guidelines (SQGs), with the exception of $\gamma-\mathrm{HCH}$. However, risks posed by concentrations of DDT observed in sediments were found to be moderate to high compared with those posed by consensus-based SQGs. Although the mean sedimentary concentrations of $\mathrm{HCH}$ and DDT found in the area of the northern Bohai Sea, China were lower than suggested SQGs in general, their concentrations in some locations were close to or above the SQGs for adverse effects in benthic organisms and, thus, remain a cause for concern.

Synthetic organochlorine pesticides (OCPs) such as hexachlorocyclohexane (HCH) and dichlorodiphenyltrichloroethane (DDT) are resistant to degradation by biological, photochemical, or chemical processes. These compounds can enter aquatic environments through effluent release, atmospheric deposition, runoff, etc., and can be transferred into food chains and, finally, accumulated in aquatic organisms (Zhou et al. 2008). As is well known, DDT was listed by the Stockholm Convention as 1 of 12 persistent organic pollutants (POPs) in 2004 (Zhu et al. 2005), and more recently, $\alpha-\mathrm{HCH}, \beta-\mathrm{HCH}$, and $\gamma-\mathrm{HCH}$ (lindane) were added to the list in 2009. Since $\mathrm{HCH}$ and DDT have an affinity for particulate matter and one of their major sinks is thought to be marine and riverine sediments (Bakan and Ariman 2004), rivers/estuaries can serve as important sources of organic contaminants to coastal marine environments and, also, act as sinks for fine-grain sediment and associated particle-reactive contaminants (Feng et al. 1998). There is growing concern over the 
environmental conditions of riverine/estuarine and coastal areas, and it has been recognized that polluted sediments can cause adverse biological effects even when water criteria are not exceeded (Liu et al. 2003). Thus, they remain a cause for concern in aquatic ecosystems.

Technical HCH and DDT were widely used in China from the 1950s until their production was officially banned in 1983 (Gong et al. 2007), however, measurable concentrations of $\mathrm{HCH}$ and DDT still exist in environmental media in China (Liu et al. 2007; Wang et al. 2007a; He et al. 2008; Zhou et al. 2008; Hu et al. 2009). From a developing-country perspective, the lack of data and information about the sources, releases, and environmental levels of persistent organic pollutants (POPs) hampers effective assessment and risk evaluation of specific compounds and indicates a great need for research (Bouwman 2004). Therefore, investigation of the concentrations of historical residues and the risks they pose in sediments from coastal regions of the northern Bohai Sea would provide a valuable record of target contaminants in aquatic environments for these areas.

The Bohai Sea, together with nearby coast and rivers/ estuaries, is a major commercial artery and has been a region of significant urbanization and industrialization (Liu et al. 2003). Its proximity to Beijing, the capitol of China, makes it one of the busiest seaways in the world. The Yellow, Liaohe, Haihe, Luanhe, and Dalinhe rivers are the major freshwater sources discharging directly into the Bohai Sea. Agriculture in these watersheds is intensive and highly productive, thus agrochemicals were used intensively to improve crop yields in these areas in the past, but their ultimate input into the coastal environment by these rivers has not been well characterized. The environmental quality in the estuarine and nearby coastal area has been severely affected by agricultural runoff and other anthropogenic inputs. Rapid social and economic development has caused this area to be contaminated with POPs (Liu et al. 2006). Because the Bohai Sea is semienclosed, water exchange with the Pacific Ocean is relatively slow, and in turn, pollutants tend to accumulate and concentrate for a long time. Hence the Bohai Sea is considered one of the most polluted marine environments in China (Zhang et al. 2009). Accordingly, the removal rate of OCPs from this semienclosed sea is slow, placing marine organisms at risk (Wu et al. 1999). Studies of contaminants in seawater, marine sediment, and biota have been conducted in the coastal areas of the Bohai Sea (Liu et al. 2007), but few studies have reported the residue levels and environmental risk of $\mathrm{HCH}$ and DDT from both marine and riverine/ estuarine sediments. Therefore, supplementary data on sediments are urgently needed for a more comprehensive understanding of the environmental quality in different environmental media of the entire region.
Results presented here were collected as part of a larger systematic investigation of concentrations and environmental risks of $\mathrm{HCH}$ and DDT in sediments from marine and adjacent riverine/estuarine areas of the northern Bohai Sea. The purposes of this study were (1) to determine concentrations of HCH and DDT in sediments from coastal regions of the northern Bohai Sea and compare these concentrations to those in sediments from other areas, (2) to elucidate the relative proportions and possible sources of $\mathrm{HCH}$ and DDT in the sediments, and (3) to identify the potential environmental risk of $\mathrm{HCH}$ and DDT in sediments. This study of historical contamination and sources of $\mathrm{HCH}$ and DDT in sediments from coastal areas of northern Bohai Sea is significant for assessing contamination potential and, also, for improving management strategies.

\section{Materials and Methods}

\section{Study Area and Sample Collection}

This study focused on the coastal and riverine/estuarine areas of the northern Bohai Sea, in northerneast China, including the following eight cities: Tangshan, Qinhuangdao, Huludao, Jinzhou, Panjin, Yinkou, Dalian, and Dandong. The Bohai Sea is a semienclosed coastal water body of the northwestern Pacific Ocean with a surface area of $\sim 7.8 \times 10^{4} \mathrm{~km}^{2}$. Benefiting from rich resources and convenient transportation, the economic contribution of the Bohai Sea amounts to one-tenth of the gross domestic product of China. Economists call the zone around the Bohai Sea "the golden necklace" of northern China.

For this survey, 10 marine sediments and 25 lake sediments were collected along the marine and adjacent riverine/estuarine areas of the northern Bohai Sea, China, in May 2008 (Fig. 1). Drainage areas of these rivers are important agricultural and chemical production areas (Wang et al. 2007a). Throughout the survey, a global positioning system (GPS) was used to locate and map all of the sampling sites. Surface sediments (top 10-cm layer) were collected using a trowel from the sedimentation basin of the bed close to the bank. Representative samples were prepared by mixing five subsamples from an area of about $5 \mathrm{~m}^{2}$. Wet samples $(\sim 1 \mathrm{~kg})$ were wrapped in polyethylene boxes and transported to the laboratory, where they were homogenized, freeze-dried, ground with a mortar and pestle, sieved using a 2-mm sieve, and stored at $4^{\circ} \mathrm{C}$ in precleaned glass jars until analysis.

Extraction, Cleanup, and Quantification

$\mathrm{HCH}$ and DDT were quantified by solid-liquid extraction followed by quantification by gas chromatography (GC) 
Fig. 1 Study area and sampling locations along the coast of the northern Bohai Sea, China

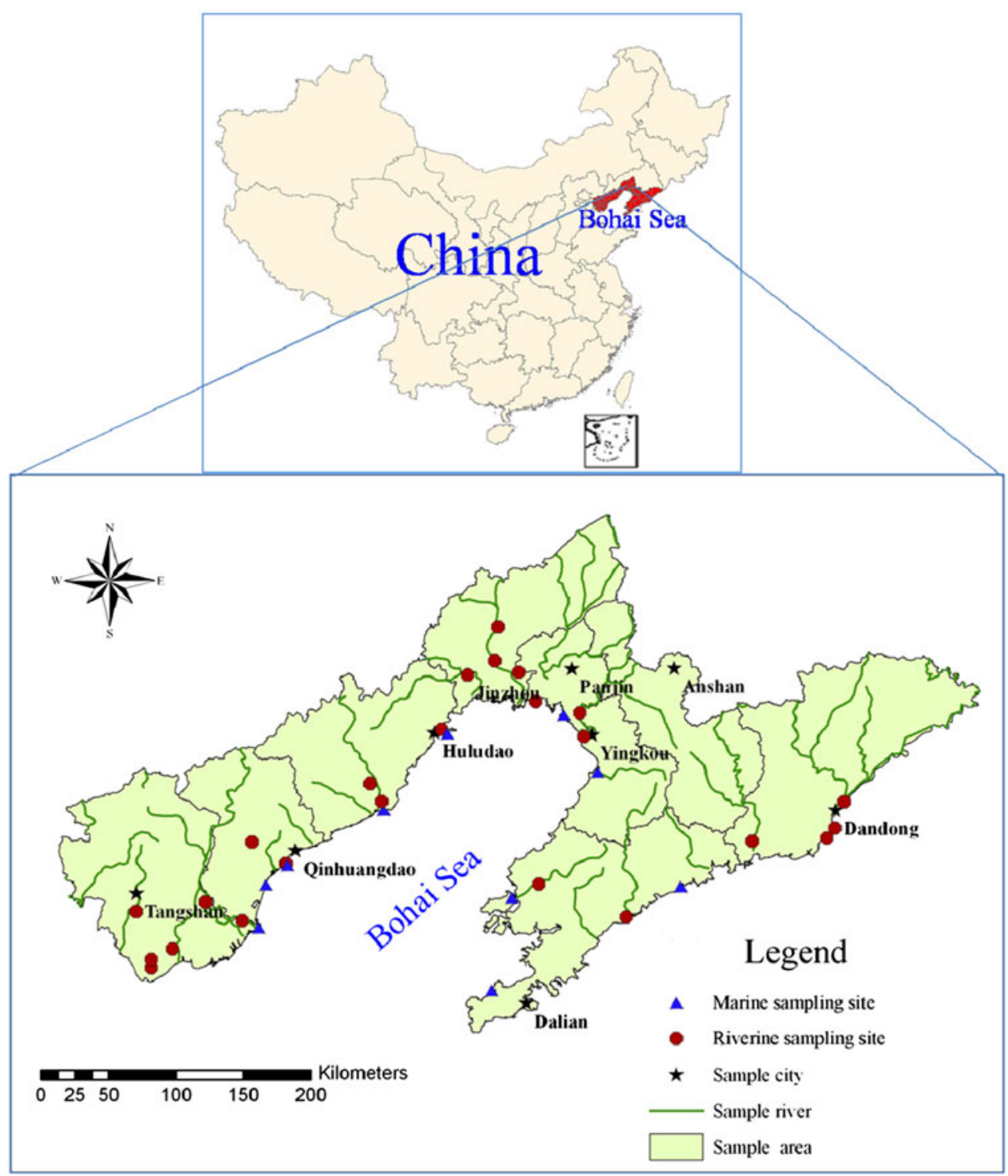

equipped with electron capture detection (Hu et al. 2009). Residues were extracted from soil with $n$-hexane and dichloromethane (J. T. Baker, HPLC grade). Anhydrous sodium sulfate (analytical grade) and silica gel (60 mesh, for column chromatography) were activated at $180^{\circ} \mathrm{C}$ for $24 \mathrm{~h}$. Solid-phase extraction (SPE; $6 \mathrm{ml}$; Supelco, Bellefonte, PA, USA) cartridges containing $1 \mathrm{~g}$ of fluorisil were washed with $10 \mathrm{ml}$ of $n$-hexane before use. Each sediment sample (5.0 $\mathrm{g}$ dry weight) was mixed with $1 \mathrm{~g}$ anhydrous sodium sulfate. One milliliter of 2,4,5,6-tetrachloro- $m$ xylene (TCMX) at the concentration of $0.08 \mu \mathrm{g} \mathrm{ml}^{-1}$ was added. The mixture was extracted twice with $35 \mathrm{ml}$ of hexane/dichloromethane $(1 / 1, \mathrm{v} / \mathrm{v})$ by ultrasonication for $60 \mathrm{~min}$ and then centrifuged. The supernatant was transferred to a K-D flask, concentrated down to about $2 \mathrm{ml}$ by rotary evaporation, and further purified with SPE cartridges loaded with $1 \mathrm{~g}$ silica gel and $1 \mathrm{~g}$ anhydrous sodium sulfate. Analytes were eluted with $20 \mathrm{ml}$ of hexane/ dichloromethane $(7 / 3, v / v)$. Eluent was concentrated to a final volume of $1 \mathrm{ml}$ for GC analysis. Reagent blanks were analyzed simultaneously with experimental samples.

A mixed standard solution containing $\alpha-, \beta-, \gamma-$, and $\delta$-HCH isomers, $p, p^{\prime}$-DDE, $p, p^{\prime}$-DDD, $o, p^{\prime}$-DDT, and $p, p^{\prime}$ DDT at $1 \mathrm{mg} \mathrm{g}^{-1}$ per compound was obtained from the National Research Center for Certified Reference Materials of China. The mass of analytes in extracts was quantified by use of an internal standard (TCMX; Supelco, Bellefonte, PA, USA). An Agilent 6890 gas chromatograph (GC) equipped with ${ }^{63} \mathrm{Ni}$ electron capture detector $(\mu \mathrm{ECD})$ (Agilent Technologies, Wilmington, DE, USA) was used for identification and quantification of $\mathrm{HCH}$ and DDT isomers. The column used was a HP-5 silica capillary column, $30 \mathrm{~m} \times 0.32-\mathrm{mm}$ i.d $\times 0.25-\mu \mathrm{m}$ film thickness. The GC- $\mu \mathrm{ECD}$ was operated in splitless injection mode 
with ultrapure nitrogen as the carrier gas and the makeup gas. The injector and detector temperatures were 220 and $300^{\circ} \mathrm{C}$, respectively. The oven temperature was initially set at $100^{\circ} \mathrm{C}$ with a 2 -min hold, ramped at $10^{\circ} \mathrm{C} \min ^{-1}$ to $160^{\circ} \mathrm{C}$ with a 2 -min hold, $4^{\circ} \mathrm{C} \mathrm{min}^{-1}$ to $230^{\circ} \mathrm{C}$ with a 5 -min hold, and $10^{\circ} \mathrm{C} \min ^{-1}$ to $270^{\circ} \mathrm{C}$ with a 2 -min hold. Four $\mathrm{HCH}$ isomers $(\alpha, \beta, \gamma$, and $\delta)$ and four DDT homologues $\left(p, p^{\prime}\right.$-DDE, $p, p^{\prime}$-DDD, $o, p^{\prime}$-DDT, and $p, p^{\prime}$-DDT) were identified by retention time matched to standards and were quantified based on peak area. Concentrations of $\sum \mathrm{HCH}$ and $\sum$ DDT were calculated by summing the four $\mathrm{HCH}$ isomers and four DDT metabolites, respectively, and are reported on a dry weight (dw) basis.

For quality assurance and control, procedural blanks and matrixes spiked with the standard solution were analyzed. None of the target compounds were detected in the procedural blanks. All solvents used were distilled in glass (PR grade) and were checked for interferences or contamination prior to use. Recoveries of four HCH isomers $(\alpha, \beta, \gamma$. and $\delta$ ) and four DDT homologues ( $p, p^{\prime}$-DDE, $p, p^{\prime}$-DDD, $o, p^{\prime}$ DDT, and $p, p^{\prime}$-DDT) spiked to sediment were $73.3 \%$, $90.3 \%, 75.8 \%$, and $85.6 \%$ and $80.0 \%, 93.8 \%, 95.4 \%$, and $96.2 \%$, respectively. Extraction efficiency, as indicated by recovery of the surrogate standards (TCMX), was $75 \pm 10 \%$. Limits of detection (LOD) were defined as three times the signal-to-noise ratio $(\mathrm{S} / \mathrm{N})$. The detection limit ranged from 0.05 to $0.20 \mathrm{ng} \mathrm{g}^{-1} \mathrm{dw}$. GC analysis was repeated twice for each replicate sample and the relative standard deviation (RSD) of replicate analyses was $<10 \%$.

\section{Data Analysis}

ArcGis (ESRI, US) was used for mapping the sampling sites. T-test was used to identify the differences in $\mathrm{HCH}$ and DDT concentrations between marine and riverine sediments using SPSS 11.5 for Windows.

\section{Results and Discussion}

\section{Concentrations of $\mathrm{HCH}$ and DDT in Sediments}

Mean concentrations of $\sum \mathrm{HCH}$ and $\sum D D T$ were 92.51 and $9.23 \mathrm{ng} \mathrm{g}^{-1} \mathrm{dw}$, ranging from <LOD to $1964.97 \mathrm{ng} \mathrm{g}^{-1} \mathrm{dw}$ and $<\mathrm{LOD}$ to $86.46 \mathrm{ng} \mathrm{g}^{-1} \mathrm{dw}$, respectively (Table 1). Concentrations of $\Sigma \mathrm{HCH}$ were higher than those of $\Sigma \mathrm{DDT}$, which accounted for $91 \%$ of the total $\mathrm{HCH}$ and DDT concentrations. This could be a result of the historical production and use of $\mathrm{HCH}$ in this region, as China was the world's largest $\mathrm{HCH}$ user. Documents about the production and pesticide application history are not available, however, based on the official application history of HCH and DDT in China and the statements of local farmers, it is likely that the
Table 1 Concentrations (ng $\left.\mathrm{g}^{-1} \mathrm{dw}\right)^{\mathrm{a}}$ of $\mathrm{HCH}$ and DDT isomers in sediments

\begin{tabular}{lrrlrll}
\hline & Mean & \multicolumn{1}{l}{ SD } & Min & \multicolumn{1}{l}{ Max } & Median & $\begin{array}{l}\text { Detection } \\
\text { rate }(\%)\end{array}$ \\
\hline$\alpha-\mathrm{HCH}$ & 0.61 & 1.66 & $<\mathrm{LOD}$ & 8.92 & 0.00 & 34.29 \\
$\beta$-HCH & 7.27 & 11.87 & $<\mathrm{LOD}$ & 51.67 & 1.69 & 77.14 \\
$\gamma-\mathrm{HCH}$ & 0.91 & 2.16 & $<\mathrm{LOD}$ & 9.24 & 0.00 & 31.43 \\
$\delta$-HCH & 83.71 & 324.64 & $<\mathrm{LOD}$ & 1920.9 & 0.30 & 82.86 \\
$\sum \mathrm{HCH}^{\mathrm{b}}$ & 92.51 & 330.44 & $<\mathrm{LOD}$ & 1964.97 & 9.07 & 97.14 \\
$p, p^{\prime}-\mathrm{DDE}$ & 1.75 & 2.3 & $<\mathrm{LOD}$ & 10.25 & 0.65 & 85.71 \\
$p, p^{\prime}-\mathrm{DDD}$ & 1.24 & 2.46 & $<\mathrm{LOD}$ & 11.59 & 0.45 & 54.29 \\
$o, p^{\prime}-\mathrm{DDT}$ & 0.79 & 2.37 & $<\mathrm{LD}$ & 13.16 & 0.00 & 22.86 \\
$p, p^{\prime}-\mathrm{DDT}$ & 5.45 & 10.89 & $<\mathrm{LOD}$ & 59.49 & 2.22 & 88.57 \\
$\sum \mathrm{DDT}^{\mathrm{c}}$ & 9.23 & 15.83 & $<\mathrm{LOD}$ & 86.46 & 5.21 & 97.14 \\
\hline
\end{tabular}

${ }^{a}$ Concentration mean, standard deviation (SD), minimum, maximum, and median were calculated assuming less than LOD (limits of detection) to be equal to zero for statistical purpose

b $\sum \mathrm{HCH}: \alpha-\mathrm{HCH}+\beta-\mathrm{HCH}+\gamma-\mathrm{HCH}+\delta-\mathrm{HCH}$

c $\sum \mathrm{DDT}: p, p^{\prime}-\mathrm{DDE}+p, p^{\prime}-\mathrm{DDD}+o, p^{\prime}-\mathrm{DDT}+p, p^{\prime}-\mathrm{DDT}$

historical application amount of $\mathrm{HCH}$ in this region was relatively greater than that of DDT. HCH isomers have been identified as a worldwide contaminant (Doong et al. 2002). The properties of higher water solubility, vapor pressure, and biodegradability, and lower lipophilicity and particle affinity, of HCH relative to DDT (Yang et al. 2005a) could account for the higher concentrations of $\mathrm{HCH}$ in sediments. These results were inconsistent with previous observations on OCP residues in freshwater sediments in China due to the difference in physicochemical and biochemical characteristics (Tang et al. 2007). Detection rates of both $\sum \mathrm{HCH}$ and $\sum$ DDT in sediments were nearly $100 \%$. The great frequency of $\mathrm{HCH}$ detection in sediments also indicated that the contamination was widespread in this study area.

Concentrations and patterns of OCPs distribution could be influenced by the chemical-physical properties of residue compounds and the environmental conditions. Topography, redox potential, and hydrodynamic condition as well as other factors all play important roles in controlling the distribution and fate of OCPs (Su et al. 2006). Looking for the site-specific distribution of the target compounds, concentrations of $\mathrm{HCH}$ and DDT in marine and riverine sediments were compared (Table 2). In marine sediments, mean concentrations of $\sum \mathrm{HCH}$ and $\sum \mathrm{DDT}$ were found to be 214.87 and $18.55 \mathrm{ng} \mathrm{g}^{-1} \mathrm{dw}$, respectively. In riverine sediments, the $\sum \mathrm{HCH}$ and $\sum \mathrm{DDT}$ were detected as mean of 43.56 and $5.51 \mathrm{ng} \mathrm{g}^{-1} \mathrm{dw}$, respectively. Concentrations of $\gamma-\mathrm{HCH}, \delta-\mathrm{HCH}, \sum \mathrm{HCH}, p, p^{\prime}-$ DDD, $o, p, p^{\prime}$-DDT, $p, p, p^{\prime}$-DDT, and $\sum \mathrm{DDT}$ in marine sediments were significantly $(p<0.05)$ higher than those of riverine sediments. After the ban on the production and application of $\mathrm{HCH}$ and DDT was enforced, the input 
Table 2 Mean $\left(\mathrm{ng} \mathrm{g}^{-1} \mathrm{dw}\right)$ and $t$-test of $\mathrm{HCH}$ and DDT between marine and riverine sediments

\begin{tabular}{|c|c|c|c|c|c|c|c|c|c|c|}
\hline & $\alpha-\mathrm{HCH}$ & $\beta-\mathrm{HCH}$ & $\gamma-\mathrm{HCH}$ & $\delta$-HCH & $\sum \mathrm{HCH}$ & $p, p^{\prime}-\mathrm{DDE}$ & $p, p^{\prime}-\mathrm{DDD}$ & $o, p^{\prime}-\mathrm{DDT}$ & $p, p^{\prime}$-DDT & $\sum D D T$ \\
\hline Marine $(n=10)$ & 0.94 & 5.1 & 1.68 & 207.16 & 214.87 & 2.11 & 3.04 & 2.35 & 11.04 & 18.55 \\
\hline Riverine $(n=25)$ & 0.48 & 8.14 & 0.61 & 34.33 & 43.56 & 1.61 & 0.52 & 0.16 & 3.22 & 5.51 \\
\hline$t$ & 0.74 & -0.68 & 1.34 & 1.45 & 1.41 & 0.58 & 3.06 & 2.68 & 2.00 & 2.34 \\
\hline$p$-value & 0.06 & 0.69 & $0.04 *$ & $0.00 * *$ & $0.00 * *$ & 0.25 & $0.00 * *$ & $0.00 * *$ & $0.02 *$ & $0.01 * *$ \\
\hline
\end{tabular}

Note: Difference is significant $*$ at the 0.05 level and $* *$ at the 0.01 level

through industrial discharge and soil erosion from agriculture soils with higher $\mathrm{HCH}$ and DDT concentrations to lake/river sediments was decreased, while the input from lake/river flow to estuary and marine environments may have served as a continuing source of the higher concentrations of $\mathrm{HCH}$ and DDT in marine sediments. The predominance of $\mathrm{HCH}$ and DDT residues in marine sediments indicated that marine sediments were more contaminated than were riverine sediments. Greater water discharge and/ or sediment loads and biogeochemical processes such as biodegradation and volatilization may be responsible for the low concentrations detected in riverine sediments $(\mathrm{Wu}$ et al. 1999). The observed variation in concentrations of $\sum \mathrm{HCH}$ and $\sum \mathrm{DDT}$ in marine and riverine sediments is likely caused by high rates of contaminant influx into estuaries through the rivers and drainage of contaminated water from the surrounding agricultural fields. Also contributing to this is the abiotic degradation of pesticides influenced by various physicochemical characteristics of the sediments, as well as microbial growth (Bakan and Ariman 2004).

\section{Comparison of $\mathrm{HCH}$ and DDT in Sediments from Other Areas}

In general, concentrations of $\mathrm{HCH}$ and DDT in sediments along the coast of the northern Bohai Sea, China, were higher than those in sediments reported from other areas (Table 3). Among the Chinese marine and riverine sediments, concentrations of $\mathrm{\sum HCH}$ in sediments from this study were the highest, with only those from Dagu Drainage River and Liaodong Bay being comparable (Yang et al. 2005b; Lu et al. 2008). Compared with other regions of the world, the mean concentration of $\sum \mathrm{HCH}$ in sediment was significantly higher than those in sediments from other areas (Table 3). The mean $\sum$ DDT concentrations observed in this study were lower than the reported

Table 3 Comparison of HCH and DDT in sediments from other coastal and river/estuary regions (ng g ${ }^{-1} \mathrm{dw}$ )

\begin{tabular}{lrrlll}
\hline Location & No. & Year & EHCH & EDDT & Reference \\
\hline Lake Dongting, China & 8 & 2004 & $0.21-9.59$ & ND-10.15 & Qian et al. (2006) \\
Catchment of Yangtze River, China & 13 & 2005 & $0.10-21.10(4.03)$ & $0.79-35.61(6.93)$ & Tang et al. (2007) \\
Liaodong Bay, China & 3 & 2006 & $20.1-103.0(68.6)$ & $7.7-76.9(42.8)$ & Lu et al. (2008) \\
Daliaohe River, China & 12 & 2005 & $1.86-21.48$ & $0.5-2.81$ & Wang et al. (2007b) \\
Haihe River, China & 40 & 2003 & $1.88-18.76(7.33)$ & $0.32-80.18(15.94)$ & Yang et al. (2005a) \\
Dagu Drainage River, China & 9 & 2003 & $33.24-141.03(87.74)$ & $3.60-83.49(35.52)$ & Yang et al. (2005a) \\
Yangtze estuary, China & 10 & 2004 & $0.5-17.5(6.0)$ & $0.9-33.1(8.2)$ & Liu et al. (2008) \\
Pearl River estuary, China & 20 & 1998 & $0.28-1.23(0.68)$ & $1.36-8.99(2.84)$ & Hong et al. 1999) \\
Songhuajiang River, China & 10 & 2007 & $2.42-7.95$ & $0.14-5.12$ & He et al. (2008) \\
Daya Bay, China & 13 & 2003 & $1.79-4.64(2.72)$ & $8.69-34.34(19.05)$ & Wang et al. (2008) \\
Victoria Harbour, Hong Kong & 10 & 1994 & ND-2.3 $(0.5)$ & $1.38-30.3(9.10)$ & Hong et al. 1995) \\
Wu-Shi River estuary, Taiwan & 19 & 1998 & $0.99-14.5(3.79)$ & $0.53-11.4(2.51)$ & Doong et al. (2002) \\
Ulsan Bay, Korea & 32 & 2000 & $0.02-4.55(0.64)$ & $0.02-41.9(3.34)$ & Khim et al. (2001) \\
Andes Mountain lakes & 17 & 1999 & $<0.005-0.23$ & $0.019-4.1$ & Borghini et al. (2005) \\
James Ross Island, Antarctica & 25 & 2005 & $0.14-0.76$ & $0.19-1.15$ & Klanova et al. (2008) \\
Black Sea coast of Samsun, Turkey & 14 & 2000 & $5-16$ & $<-55$ & Bakan and Ariman (2004) \\
Coast of Bohai Sea, China & 35 & 2008 & $<$ LOD-1964.97 (92.51) & $<6.46(9.23)$ & This study \\
\hline
\end{tabular}

$N D$ under detectable limit, $L O D$ limit of detection 
mean $\sum$ DDT concentrations in sediments from Liaodong Bay, Haihe River, Dagu Drainage River, and Daya Bay. However, the mean $\sum D D T$ concentration was higher than in the other areas in China (Table 3). The mean $\sum$ DDT concentration observed in this study was also higher than those reported for Ulsan Bay Korea, Mountain Andean Lakes, James Ross Island, Antarctica, and the Black Sea coast of Samsun, Turkey (Table 3). The relatively higher concentrations of $\mathrm{HCH}$ and DDT in sediments along the coast of the northern Bohai Sea than in sediments from other areas is most likely due to higher historical applications of $\mathrm{HCH}$ and DDT in this region. According to our investigation, agriculture in this region is intensive and highly productive, thus agrochemicals were used intensively to improve crop yields in this area in the past.

Relative Proportions of $\mathrm{HCH}$ and DDT Components and Possible Sources

$\mathrm{HCH}$ is one of the most widely used and most readily detected OCPs in environmental samples. It was used either as the technical $\mathrm{HCH}$ mixture (a formulation dominated by the $\alpha$-isomer) or as lindane (a formulation containing almost $100 \%$ of the $\gamma$-isomer) (Chrysikou et al. 2008). The typical technical HCH generally contains $55-$ $80 \% \alpha-\mathrm{HCH}, 5-14 \% \beta-\mathrm{HCH}, 8-15 \% \gamma-\mathrm{HCH}$, and $2-16 \%$ $\delta$-HCH (Yang et al. 2005b). The physicochemical properties of these $\mathrm{HCH}$ isomers are different, which leads to differential partitioning in the environment. Among the $\mathrm{HCH}$ isomers, $\alpha-\mathrm{HCH}$ is more likely to partition to the air and transport over long distances, while $\beta-\mathrm{HCH}$ is more resistant to hydrolysis and environmental degradation and is the dominant isomer in soils, animal tissue, and fluids (Willett et al. 1998). After long-term migration and transformation, $\beta-\mathrm{HCH}$ is generally the dominant isomer in sediments of rivers or estuaries (Yang et al. 2005b). In this study, the relative proportions of $\alpha-, \beta-, \gamma$, and $\delta$-HCH were $1 \%, 8 \%, 1 \%$, and $90 \%$, respectively, with a greater proportion of $\delta$-HCH observed. This pattern is different from the relative proportions of typical technical $\mathrm{HCH}$. $\delta$ $\mathrm{HCH}$ has the longest half-life of $\mathrm{HCH}$ isomers (Satpathy et al. 1997). Thus, it was the most heavily polluted isomer, although its original level was not higher. $\beta$ - $\mathrm{HCH}$ is the least water-soluble isomer of $\mathrm{HCH}$, has a higher vapor pressure and octanol/water partitioning coefficient, and is relatively resistant to microbial degradation, which makes it the most stable isomer (Willett et al. 1998; Yang et al. $2005 b)$. After a long period of weathering, $\alpha$ - and $\gamma-\mathrm{HCH}$ can be transformed into $\beta$-HCH (Yang et al. 2005a). The observation of a greater relative proportion of $\beta-\mathrm{HCH}(8 \%$ of $\sum \mathrm{HCH}$ ) than $\alpha$ - and $\gamma-\mathrm{HCH}$ indicated that the $\mathrm{HCH}$ was mainly due to historical use (Toan et al. 2007) and that technical $\mathrm{HCH}$ has not recently been used in this region. The relatively small proportion of $\gamma$ - $\mathrm{HCH}$ further supports the conclusion that there are few new inputs of $\mathrm{HCH}$.

Because the use of DDT in China was banned in the early 1980s, the presence of DDT in the sediment was thought to be predominantly from historical usage. DDT undergoes slow degradation to DDD and DDE in the natural environment by chemical and biological processes (Yuan et al. 2001). The ratios of various degradation products may, therefore, reflect some of the effects of environmental conditions on the degradation process (Yuan et al. 2001). The ranking of relative concentrations of DDT metabolites were found to be in the order $p, p^{\prime}$-DDT (59\%), $p, p^{\prime}$-DDE (19\%), $p, p^{\prime}$-DDD (13\%), $o, p^{\prime}$-DDT (9\%). The relatively high concentration of DDT relative to DDD and DDE in these samples indicated either that there was minimal degradation of DDT in this region or that there has been more recent input of technical DDT at some sampling locations (Yuan et al. 2001). One possibility is that, after the ban on the use of DDT in agricultural production, the input of agricultural application was cut, while weathered agricultural soils and atmospheric deposition might have served as continuing input sources (Villa et al. 2003; Gioia et al. 2005). It has been reported that washout of DDT from soils was a process which possibly caused increasing concentrations of DDT in recent years (Santschi et al. 2001). Coastal cities around the Bohai Sea experienced rapid economic development and largescale land reclamation in the early 1990 s, which has led to serious soil erosion along the Liaohe and Luanhe rivers. Therefore, DDT residues in agricultural soil transported by enhanced surface runoff to the sediments may be the major reason for the increase in DDT concentrations in riverine and marine sediments. As a whole, results obtained in this study indicate that DDT in sediments may be derived from aged and weathered agricultural soils and transported by surface runoff and atmospheric deposition to the marine and riverine sediments. The predominance of DDE over DDD in these sediments indicates reductive dechlorination of DDT to DDE under anaerobic conditions. Differences in the relative concentrations of DDD and DDE in the sediment samples indicated different environmental conditions under which DDT was degraded. In addition, the Bohai Sea is an open system with active hydrodynamic processes. The aerobic conditions in marine and riverine environment may favor the microbial metabolization of DDT to DDE, which would result in the greater proportions of DDE and lesser proportions of DDD (Yuan et al. 2001).

Environmental Risk Assessment of HCH and DDT in Sediments

The status and trends of $\mathrm{HCH}$ and DDT and potential sources are significant factors in the management and 
long-term conservation of marine ecosystems (SzlinderRichert et al. 2008). The ecological effects of pesticides are varied and often complex. Effects at the organism or ecosystem level are usually considered to be an early warning indicator of potential human health impacts (Qian et al. 2006). Due to the complex nature of sediments, it is difficult to determine the potential effects of pollutants including $\mathrm{HCH}$ and DDT in sediments. Despite the fact that many studies have been conducted, there is no uniform standard available for sediments (McCauley et al. 2000). In China, no environmental standards have been established for $\mathrm{HCH}$ or DDT in marine or riverine sediments. Therefore, in this study, the environmental risks of $\mathrm{HCH}$ and DDT in sediments were compared to published numerical sediment quality guidelines (SQGs) including thresholdeffect concentrations (TECs) and probable-effect concentrations (PECs) (MacDonald et al. 2000; Tang et al. 2007). It is understood that these published values are not accurate representations of the probability of actual effects and may overestimate the potential risks. However, in the absence of other criteria, they can be used as a reference point to indicate the relative potential for effects at this time.

Concentrations of $\mathrm{HCH}$ and DDT in marine, riverine, and all sediments were compared to SQGs (Table 4). Overall, concentrations of $\mathrm{HCH}$ and DDT in marine sediments posed relatively greater environmental risks compared to riverine sediments. Concentrations of $\alpha-\mathrm{HCH}$ in most sediments were found to be lower than the lowest effect level (LEL). Although SQGs for $\gamma$-HCH varied depending on the guidelines, mean concentrations of $\gamma$-HCH (1.68 $\left.\mathrm{ng} \mathrm{g}^{-1} \mathrm{dw}\right)$ in marine sediment exceed some TEC (0.94 $\mathrm{ng} \mathrm{g}^{-1} \mathrm{dw}$ TEL) and PEC (1.38 $\mathrm{ng} \mathrm{g}^{-1} \mathrm{dw}$ PEL) values, indicating that there is the potential for adverse effects on some species inhabiting sediments (Sarkar et al. 2008). In general, the concentrations of $\alpha$ - and $\gamma-\mathrm{HCH}$ in most sediments from the riverine and coastal areas of the northern Bohai Sea were lower than the suggested guidelines, thus the current concentrations of these isomers present little risk to marine benthic organisms. $\delta$ - and $\beta$ - $\mathrm{HCH}$ were the predominant isomers, representing $90 \%$ and $8 \%$ of the $\sum \mathrm{HCH}$, respectively, observed in this study, but there are no criteria established for these isomers in sediments. While the exact potential risks of $\delta$ - and $\beta$-HCH are unknown, they must still be considered to represent a potential concern when assessing sediments. Meanwhile, the potential risk caused by the measured concentrations of DDT was found to be relatively high compared to that of $\mathrm{HCH}$ isomers. For example, concentrations of DDT for over $80 \%$ and $60 \%$ of marine sediment samples exceeded the ERL (effect range low; adverse effects in $10 \%$ of tests in the Biological Effects Database) and ERM (effect range median; adverse effects in 50\% of tests), respectively. As is well known, the ERL values indicated possible adverse biological effects on aquatic organisms and the ERM values suggested a good possibility of the posing of detrimental biological effects on aquatic organisms (Long and Morgan 1991; Tang et al. 2007). The potential for effects of DDT in these sediments was considered to be moderate to high at this time. Concentrations of $\sum$ DDT also exceeded the ERM in some riverine sediments of the Liaohe, Luanhe, and Yalu rivers. In general, the observed concentrations of DDT pollution were sufficient to potentially cause adverse effects on benthic invertebrates in both marine and riverine sediments, especially at locations where the highest concentrations of DDT were observed. Continuing research effort is necessary to establish the most appropriate indicators to be used in describing coastal conditions and also to provide the appropriate weighting factors to be combined for an overall assessment of OCPs including $\mathrm{HCH}$ and DDT in marine and riverine areas in China (EPA 2001).

Table 4 Comparison between HCH and DDT levels in this study and sediment concentrations as guideline values (ng g $\mathrm{g}^{-1} \mathrm{dw}$ )

\begin{tabular}{|c|c|c|c|c|c|c|c|c|c|c|c|}
\hline \multirow[t]{2}{*}{$\mathrm{OCP}$} & \multicolumn{4}{|l|}{ TEC } & \multicolumn{4}{|l|}{ PEC } & \multicolumn{3}{|c|}{ OCPs in sediments: range (mean) } \\
\hline & TEL & LEL & ERL & CB-TEC & PEL & SEL & ERM & CB-PEC & Marine $(n=10)$ & Riverine $(n=25)$ & All samples $(n=35)$ \\
\hline$\alpha-\mathrm{HCH}$ & NA & 6 & NA & NA & NA & NA & NA & NA & ND-8.92 (0.94) & $0.26-3.42(0.48)$ & ND-8.92 (0.61) \\
\hline$\gamma-\mathrm{HCH}$ & 0.94 & 3 & NA & 2.37 & 1.38 & 10 & NA & 4.99 & ND-9.24 (1.68) & ND-7.56 (0.61) & ND-9.24 (0.91) \\
\hline DDE & 1.42 & 5 & 2 & 3.16 & 6.75 & 190 & 15 & 31.3 & ND-10.25 (2.11) & ND-6.27 (1.61) & ND-10.25 (1.75) \\
\hline DDD & 3.54 & 8 & 2 & 4.88 & 8.51 & 60 & 20 & 28.0 & ND-11.59 (3.04) & ND-2.60 (0.52) & ND-11.59 (1.24) \\
\hline DDT & NA & 8 & 1 & 4.16 & NA & 710 & 7 & 62.9 & ND-72.65 (13.09) & ND-33.26 (3.50) & ND-72.65 (6.24) \\
\hline$\Sigma$ DDT & 7 & 7 & 3 & 5.28 & 4450 & 120 & 350 & 572 & $0.97-86.46(18.55)$ & ND-42.13 (5.51) & ND-86.46 (9.23) \\
\hline
\end{tabular}

$T E C$ threshold-effect concentration, $P E C$ probable-effect concentration, $T E L$ threshold-effect level, $P E L$ probable-effect level, $L E L$ lowest-effect level, $S E L$ severe-effect level, $E R L$ effect range low, $E R M$ effects range median, $C B$ - $T E C$ consensus-based TEC, $C B-P E C$ consensus-based PEC (MacDonald et al. 2000; Tang et al. 2007), $N A$ not available, $N D$ under detection limit. ERL: the concentration of a contaminant that will result in adverse effects in $\sim 10 \%$ of tests in the Biological Effects Database. ERM: the concentration of a contaminant that will result in adverse effects in $\sim 50 \%$ of tests. ERL and ERM values are from Long and Morgan (1991) and Long et al. (1995) 


\section{Conclusions}

Concentrations of $\mathrm{HCH}$ and DDT were higher in marine than in river sediments. Concentrations of $\mathrm{HCH}$ and DDT in sediments of the northern Bohai Sea were higher than in other coastal regions. The origin of $\mathrm{HCH}$ in sediments was primarily historical use, while DDT enters the sea from a combination of erosion of weathered soils and long-range atmospheric transport. Concentrations of $\alpha-$ and $\gamma-\mathrm{HCH}$ in the study area did not exceed benchmark values and are thus of little concern, while the potential risk of $\delta$ - and $\beta$-HCH is still of concern. Risks posed by the concentrations of DDT observed in sediments were deemed to be moderate to high, warranting a continuing research effort.

Acknowledgments This study was supported by the National Basic Research Program of China ("973" Research Program) under Grant No.2007CB407307, the National S\&T Support Program under Grant No.2008BAC32B07, the Knowledge Innovation Program of the Chinese Academy of Sciences under Grant No.KZCX2-YW-420-5, and the National Natural Science Foundation of China under Grant No.40601089. Portions of the research were supported by a Discovery Grant from the National Science and Engineering Research Council of Canada (Project No. 326415-07) and a grant from the Western Economic Diversification Canada (Project Nos. 6971 and 6807). Professor Giesy's participation in the project was supported by the Einstein Professorship Program of the Chinese Academy of Sciences. We also thank the editors and reviewers for valuable comments and suggestions.

\section{References}

Bakan G, Ariman S (2004) Persistent organochlorine residues in sediments along the coast of mid-Black Sea region of Turkey. Mar Pollut Bull 48:1031-1039

Borghini F, Grimalt JO, Sanchez-Hernandez JC, Barra R, Garcia CJT, Focardi S (2005) Organochlorine compounds in soils and sediments of the mountain Andean Lakes. Environ Pollut 136:253-266

Bouwman H (2004) South Africa and the Stockholm Convention on persistent organic pollutants. S Afr J Sci 100(7-8):323-328

Chrysikou L, Gemenetzis P, Kouras A, Manoli E, Terzi E, Samara C (2008) Distribution of persistent organic pollutants, polycyclic aromatic hydrocarbons and trace elements in soil and vegetation following a large scale landfill fire in northern Greece. Environ Int 34:210-225

Doong RA, Peng CK, Sun YC, Liao PL (2002) Composition and distribution of organochlorine pesticide residues in surface sediments from the Wu-Shi River estuary, Taiwan. Mar Pollut Bull 45:246-253

EPA (2001) National coastal condition report. EPA-620/R-01/005. U.S. Environmental Protection Agency, Washington, DC

Feng H, Cochran JK, Lwiza H, Brownawell BJ, Hirschberg DJ (1998) Distribution of heavy metal and PCB contaminants in the sediments of an urban estuary: the Hudson River. Mar Environ Res 45:69-88

Gioia R, Offenberg JH, Gigliotti CL, Totten LA, Du S, Eisenreich SJ (2005) Atmospheric concentrations and deposition of organochlorine pesticides in the US Mid-Atlantic region. Atmos Environ 39:2309-2322
Gong XY, Qi SH, Wang YX, Julia EB, Lv CL (2007) Historical contamination and sources of organochlorine pesticides in sediment cores from Quanzhou Bay, Southeast China. Mar Pollut Bull 54:1434-1440

He M, Wang H, Lin C, Quan X, Guo W, Yang Z (2008) Distribution of persistent organochlorine residues in sediments from the Songhuajiang River, northeast China. Environ Technol 29:303-314

Hong H, Xu L, Zhang L, Chen JC, Wong YS, Wan TSM (1995) Special guest paper: Environmental fate and chemistry of organic pollutants in the sediment of Xiamen and Victoria harbours. Mar Pollut Bull 31:229-236

Hong HS, Chen WQ, Xu L, Wang XH, Zhang LP (1999) Distribution and fate of organochlorine pollutants in the Pearl River estuary. Mar Pollut Bull 39:376-382

Hu WY, Lu YL, Wang TY, Luo W, Zhang X, Geng J, Wang G, Shi YJ, Jiao WT, Chen CL (2009) Factors affecting HCH and DDT in soils around watersheds of Beijing reservoirs, China. Environ Geochem Health. doi:10.1007/s10653-009-9267-0

Khim JS, Lee KT, Kannan K, Villeneuve DL, Giesy JP, Koh CH (2001) Trace organic contaminants in sediment and water from Ulsan Bay and its vicinity, Korea. Arch Environ Contam Toxicol 40:141-150

Klanova J, Matykiewiczova N, Macka Z, Prosek P, Laska K, Klan P (2008) Persistent organic pollutants in soils and sediments from James Ross Island, Antarctica. Environ Pollut 152:416-423

Liu M, Yang Y, Hou L, Xu S, Ou D, Zhang B, Liu Q (2003) Chlorinated organic contaminants in surface sediments from the Yangtze Estuary and nearby coastal areas, China. Mar Pollut Bull 46:672-676

Liu WX, Chen JL, Lin XM, Tao S (2006) Distribution and characteristics of organic micropollutants in surface sediments from Bohai Sea. Environ Pollut 140:4-8

Liu W, Chen J, Lin X, Fan Y, Tao S (2007) Residual concentrations of micropollutants in benthic mussels in the coastal areas of Bohai Sea, North China. Environ Pollut 146:470-477

Liu M, Cheng SB, Ou DN, Yang Y, Liu HL, Hou LJ, Gao L, Xu SY (2008) Organochlorine pesticides in surface sediments and suspended particulate matters from the Yangtze estuary, China. Environ Pollut 156:168-173

Long ER, Morgan LG (1991) The potential for biological effects of sediment-sorbed contaminants tested in the National Status and Trends Program. NOAA Technical Memorandum NOS OMA 52. National Oceanic and Atmospheric Administration, Seattle, WA

Long ER, Macdonald DD, Smith SL, Calder FD (1995) Incidence of adverse biological effects within ranges of chemical concentrations in marine and estuarine sediments. Environ Manage 19:81-97

Lu R, Qing Y, Zhen B, Zhang L (2008) Study on the ultrasonic extraction method of organochlorine pesticides in the sediments. Res Environ Sci 23(3):135-140 (in Chinese)

MacDonald DD, Ingersoll CG, Berger TA (2000) Development and evaluation of consensus-based sediment quality guidelines for freshwater ecosystems. Arch Environ Contam Toxicol 39:20-31

McCauley DJ, DeGraeve GM, Linton TK (2000) Sediment quality guidelines and assessment: overview and research needs. Environ Sci Policy 3:133-144

Qian Y, Zheng MH, Zhang B, Gao LR, Liu WB (2006) Determination and assessment of HCHs and DDTs residues in sediments from Lake Dongting, China. Environ Monit Assess 116:157-167

Santschi PH, Presley BJ, Wade TL, Garcia-Romero B, Baskaran M (2001) Historical contamination of PAHs, PCBs, DDTs, and heavy metals in Mississippi River Delta, Galveston Bay and Tampa Bay sediment cores. Mar Environ Res 52:51-79

Sarkar SK, Bhattacharya BD, Bhattacharya A, Chatterjee M, Alam A, Satpathy KK, Jonathan MP (2008) Occurrence, distribution and possible sources of organochlorine pesticide residues in tropical 
coastal environment of India: an overview. Environ Int 34: 1062-1071

Satpathy SN, Rath AK, Mishra SR, Kumaraswamy S, Ramakrishnan B, Adhya TK, Sethunathan N (1997) Effect of hexachlorocyclohexane on methane production and emission from flooded rice soil. Chemosphere 34:2663-2671

Su QK, Qi SH, Wu CX, Julia EB, Liu HF, Fang M, Li J, Zhang G (2006) Organochlorine pesticides in marine environment of Quanzhou Bay, Southeast China. Chinese J Geochem 25(B08): 190

Szlinder-Richert J, Barska I, Mazerski J, Usydus Z (2008) Organochlorine pesticides in fish from the southern Baltic Sea: levels, bioaccumulation features and temporal trends during the 19952006 period. Mar Pollut Bull 56:927-940

Tang ZW, Yang ZF, Shen ZY, Niu JF, Liao RF (2007) Distribution and sources of organochlorine pesticides in sediments from typical catchment of the Yangtze River, China. Arch Environ Contam Toxicol 53:303-312

Toan VD, Thao VD, Walder J, Schmutz HR, Ha CT (2007) Contamination by selected organochlorine pesticides (OCPs) in surface soils in Hanoi, Vietnam. Bull Environ Contam Toxicol 78:195-200

Villa S, Vighi M, Maggi V, Finizio A, Bolzacchini E (2003) Historical trends of organochlorine pesticides in an Alpine glacier. J Atmos Chem 46:295-311

Wang HZ, He MC, Lin C, Quan XC, Guo W, Yang ZF (2007a) Monitoring and assessment of persistent organochlorine residues in sediments from the Daliaohe river watershed, Northeast of China. Environ Monit Assess 133:231-242

Wang Y, Yang R, Jiang G (2007b) Investigation of organochlorine pesticides (OCPs) in mollusks collected from coastal sites along the Chinese Bohai Sea from 2002 to 2004. Environ Pollut 146:100-106

Wang Z, Yan W, Chi J, Zhang G (2008) Spatial and vertical distribution of organochlorine pesticides in sediments from Daya Bay, South China. Mar Pollut Bull 56:1578-1585

Willett KL, Ulrich EM, Hites RA (1998) Differential toxicity and environmental fates of hexachlorocyclohexane isomers. Environ Sci Technol 32:2197-2207

Wu Y, Zhang J, Zhou Q (1999) Persistent organochlorine residues in sediments from Chinese river/estuary systems. Environ Pollut 105:143-150

Yang RQ, Jiang GB, Zhou QF, Yuan CG, Shi JB (2005a) Occurrence and distribution of organochlorine pesticides ( $\mathrm{HCH}$ and DDT) in sediments collected from East China Sea. Environ Int 31: 799-804

Yang RQ, Lv AH, Shi JB, Jiang GB (2005b) The levels and distribution of organochlorine pesticides (OCPs) in sediments from the Haihe River, China. Chemosphere 61:347-354

Yuan D, Yang D, Wade TL, Qian Y (2001) Status of persistent organic pollutants in the sediment from several estuaries in China. Environ Pollut 114:101-111

Zhang P, Song J, Yuan H (2009) Persistent organic pollutant residues in the sediments and mollusks from the Bohai Sea coastal areas, North China: an overview. Environ Int 35:632-646

Zhou RB, Zhu LZ, Kong QX (2008) Levels and distribution of organochlorine pesticides in shellfish from Qiantang River, China. J Hazard Mater 152:1192-1200

Zhu YF, Liu H, Xi ZQ, Cheng HX, Xu XB (2005) Organochlorine pesticides (DDTs and $\mathrm{HCHs}$ ) in soils from the outskirts of Beijing, China. Chemosphere 60:770-778 